\title{
Key Parameters of Breakwater Layout in Muddy Port of Lianyungang
}

\author{
Qixiu Pang
}

\begin{abstract}
- the methods to determine the key parameters of the breakwater layout, such as the direction, and the position of breakwater head, need to be verified and improved by more projects. Therefore, breakwater of Ganyu Port Area of Lianyungang Harbor was selected to be an example. Results show that breakwater direction can be determined mainly considering the wave prevention and water flow regulation, and position of breakwater head may be mainly based on the planar distribution of suspend sediment concentration (SSC), particularly the SSC under the action of strong wind wave, as well as the location of surf zone. Further, the schemes of breakwater layout need to be optimized by means of numerical models and physical models. Finally, the breakwater layout determined using these methods also needs to be verified with the field data investigated after the Starting project. The results have proved that the layout determined by the methods is really reasonable. Hence, the methods to determine breakwater layout might be as reference for the design of other new breakwater.
\end{abstract}

Index Terms-Breakwater layout, breakwater head, breakwater direction, Lianyungang.

\section{INTRODUCTION}

Wave and sediment siltation are main problems of harbors in the open muddy coast. Therefore, the purpose of breakwater is more than wave prevention, and it is also an important engineering to reduce the amount of siltation [1], [2]. Thus, fthe layout of breakwater is one of the most important questions for the design of a harbor. For the layout of breakwater, the common problems might be how to determine the key parameters such as breakwater direction, position of breakwater head etc. [3]. The methods to solve these problems need to be verified and improved constantly through more projects. Hence, the breakwater layout of Ganyu Port Area of Lianyungang Harbor, as an example, were determined by field investigation and analysis of key hydrodynamic and sediment characteristics including wave, tidal current and suspend sediment concentration (SSC). And then, these key layout parameters were verified and optimized by means of numerical model and physical model. In the end, the field data surveyed after the completion of starting project were employed to prove the rationality of layout.

Manuscript received August 31, 2016; revised October 13, 2016. This paper is funded by the National High Technology Research and Development Program ("863"Program) of China (2012AA112509).

The author is with Tianjin Research Institute of Water Transport Engineering, National Engineering Laboratory for Port Hydraulic Construction Technology, Key Laboratory of Engineering sediment of Ministry of Transport, P. R. China (e-mail: pangqixiu@163.com).

\section{METHODS}

\section{A. Field Investigation}

Port of Lian Yungang is in the Northeast coast of Jiangsu Province, locating at latitude $34^{\circ} 44^{\prime}$ and longitude $119^{\circ} 27^{\prime}$. Ganyu Port Area of Lianyungang Harbor Locates in Haizhou Bay, as shown in Fig. 1. In order to obtain the characteristics of wave, flow and sediment, lots of field survey work were carried out including: (1) a wide range of sediment sampling and particle analysis test; (2) hydrological survey in the normal sea conditions, for example, 5 stations named as SW1 to SW5 in Fig.2; and (3) hydrological survey i.e. synchronous observation of wave, tide current and SSC with self-contained apparatus in days with strong wind wave, which were carried out at three stations respectively with bottom elevation of $-3 \mathrm{~m},-5.5 \mathrm{~m}$ and $-8 \mathrm{~m}$ along the designed waterway axis with the names of station $\mathrm{S} 1$ to $\mathrm{S} 3$ as shown in Fig. 2, on August 10 to 12, 2009. The wind scale was about 7 to 8 .

In addition, long time wave data recorded from 1962 to 2003 were collected from Daxishan marine station near Lianyungang harbor, and wave data observed from July 2003 to May 2005 in Lanshan harbor as well. The sites of two wave observation stations are illustrated as in Fig. 1.

Further, these data was analyzed to obtain the key characteristics of wave, and tidal current, and sediment, which are the basis to determine the key parameters of breakwater layout.

\section{B. Numerical Model Test}

\section{1) Numerical model of wave}

Wave was simulated with SW modules of Mike software, considering the effects of bottom friction, shoaling, refraction, crushing, nonlinear effect, diffraction and reflection during the wave propagation [4], [5]. The computational domain was subdivided with triangular meshes.

\section{2) Numerical model of tidal current and sediment}

2-D numerical models of tidal current and sediment were established, which can take into account the effect of wind and wave at the same time [6]. Three nesting models with large, medium and small sizes were established, which ranges are as shown in Fig.1. Triangular meshes were also used, and the minimum mesh sizes of the small model were $40 \mathrm{~m}$, and the time steps were $10 \mathrm{~s}$. The numerical models of tidal current use the two-dimensional shallow water equations integrated with Navier-Stokes equations along the water depth as followed [7]. 


$$
\begin{gathered}
\frac{\partial \zeta}{\partial t}+\frac{\partial U H}{\partial x}+\frac{\partial V H}{\partial y}=0 \\
\frac{\partial U}{\partial t}+U \frac{\partial U}{\partial x}+V \frac{\partial U}{\partial y}-f V=-\frac{\partial}{\partial x}\left\lfloor\frac{p_{\zeta}}{\rho_{0}}+g \zeta-g(\eta+\gamma)\right\rfloor+\frac{\tau_{s c}}{\rho_{0} H}-\frac{\tau_{b x}}{\rho_{0} H}+D_{x}-B_{x} \\
\frac{\partial V}{\partial t}+U \frac{\partial V}{\partial x}+V \frac{\partial V}{\partial y}-f U=-\frac{\partial}{\partial y}\left\lfloor\frac{p_{\zeta}}{\rho_{0}}+g \zeta-g(\eta+\gamma)\right\rfloor+\frac{\tau_{g}}{\rho_{0} H}-\frac{\tau_{b y}}{\rho_{0} H}+D_{y}-B_{y}
\end{gathered}
$$

where, $x$ and $y$ represent the horizontal and vertical coordinates; $t$ is the time; $U$ and $V$ are respectively the depth average velocity along the direction of ${ }^{x}$ and ${ }^{y} ; \zeta$ is the height above the average water level; $H$ is the total water depth; ${ }^{t}$ is the coefficient of Coriolis force; ${ }^{p}$ is the surface pressure; $\rho_{0}$ is the water density; $\tau_{s x}$ and ${ }^{\tau_{s y}}$ are surface (wind stress) and bottom shear stress; ${ }^{\tau_{b x}}$ and ${ }^{\tau_{b y}}$ represent the friction; $D_{x}$ and $D_{y}$ are the diffusion; $B_{x}$ and $B_{y}$ are the baroclinic pressure gradient; $(\eta+\gamma)$ means the effect of Newton tidal potential and the earth tide; $g$ is the acceleration of gravity.

The sediment mathematical models use the two-dimensional suspended sediment convection diffusion equation as followed [7].

$$
\begin{gathered}
\frac{\partial[(h+\zeta) C]}{\partial t}+\frac{\partial[(h+\zeta) u C]}{\partial x}+\frac{\partial[(h+\zeta) C v]}{\partial y}= \\
-F_{s}+\frac{\partial}{\partial x}\left[(h+\zeta) D_{x} \frac{\partial C}{\partial x}\right]+\frac{\partial}{\partial y}\left[(h+\zeta) D_{y} \frac{\partial C}{\partial y}\right]
\end{gathered}
$$

where, $C$ is the suspend sediment concentration; $F_{s}$ is the function of scouring and silting.

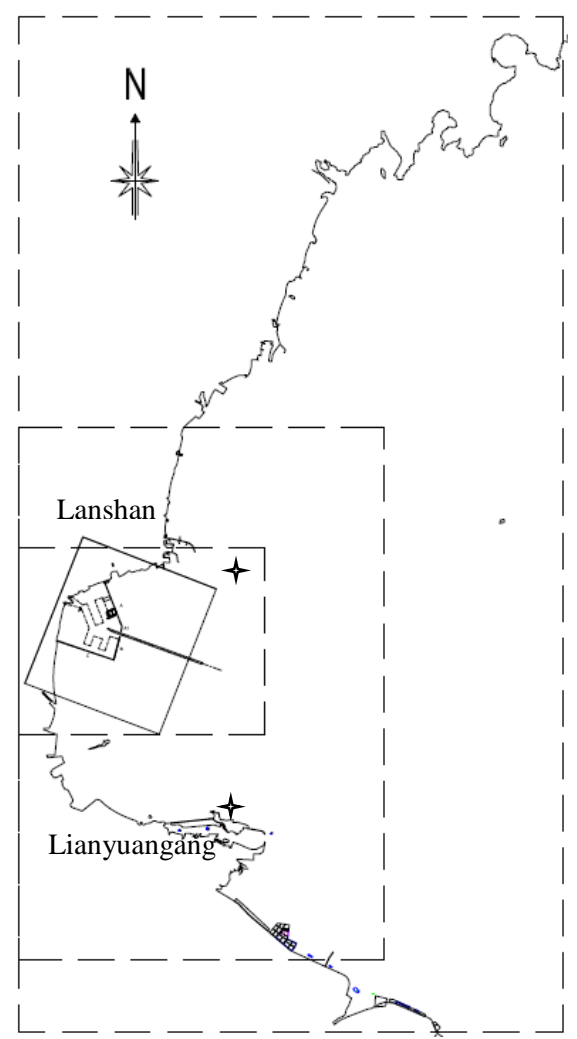

Fig. 1. Location of the projects and the scope of numerical models (three nesting models with dashed quadrangle) and physical model (solid quadrangle), and two wave observation stations (star).

\section{Physical Model Test}

On the basis of the characteristics of hydrodynamic and sediment, a physical model of sediment motion under the action of waves and tidal currents was built. The model was based on the principle of similarity of flow motion, wave motion and sediment movement. The sand used in the model was selected according to the principle of similar settlement. Model edges are shown in Fig.1, which ranges were about $29 \mathrm{~km}$ along the shore direction, and about $21 \mathrm{~km}$ in the offshore direction. According to the size of the test ground, the plane scales of model were 1:480, and the vertical scales were $1: 80$.

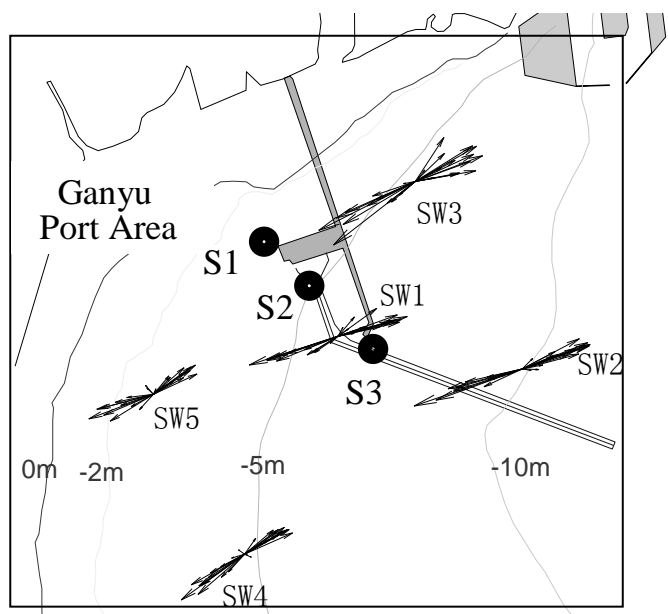

Fig. 2. Location of station SW1 to SW5 for hydrological survey under the normal sea conditions as well as the vectors of tidal current; location of station S1 to S3 for hydrological survey with self-contained apparatus in blustery day. It should be noted that the breakwater and channel had not been built when these hydrological survey carried out.

\section{RESULTS}

\section{A. Layout of the Breakwater}

1) Determination of the breakwater direction

The direction of breakwater was determined mainly considering the purpose of wave prevention and water flow regulation.

According to the wave data observed by Daxishan Marine Station, normal wave directions are NE and $\mathrm{E}$ with frequency of $26.41 \%$ and $18.40 \%$ respectively, and strong wave directions are NNE and NE, as illustrated in Fig. 3 (Top). Whereas, statistic wave characteristics from Lanshan station present that normal wave direction is $\mathrm{E}$ with frequency of $26.3 \%$, and strong wave directions are $\mathrm{E}$ and NE, as shown in Fig.3 (Bottom). Therefore, the wave characteristics of Lanshan station and Daxishan marine station are not the same completely, but the normal wave directions are basically E, and the strong wave directions are about $\mathrm{E}$ to NNE.

Based on the hydrological survey data, the tide of Haizhou Bay belongs to the regular semi diurnal tide, and the main directions of flooding tidal current are from NE to SW, and inversely in ebb, as illustrated in Fig. 2.

Therefore, for the sake of wave prevention, the breakwater should be mainly to cover the wave from the directions of NNE to E. Meantime, the direction of outer section of the breakwater should be SW to NE, considering the smooth flow. 

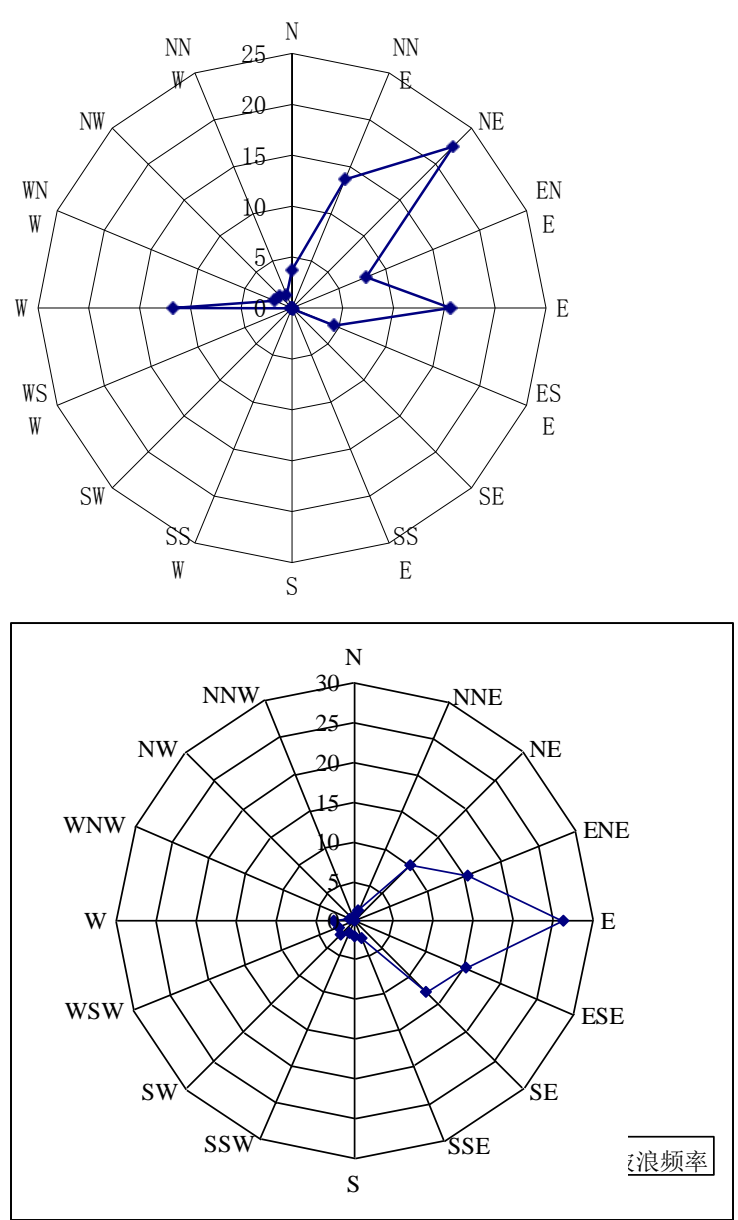

Fig. 3. Statistic wave frequency from the Daxishan marine station (top) and the Lanshan station (bottom).

\section{2) Determination of breakwater head position}

Position of breakwater head is determined mainly based on the planar distribution of SSC, especially SSC under the action of strong wave, and the location of surf zone.

According to the field data surveyed many times in normal sea conditions, the vertical average SSC of Haizhou Bay is generally about 0.03 to $0.2 \mathrm{~kg} / \mathrm{m}^{3}$, and the maximum is approximately 0.06 to $0.3 \mathrm{~kg} / \mathrm{m}^{3}[8]$. However, under the action of strong wind, the SSC is quite different. Fig.4 is the time variation of SSC at the height of $0.5 \mathrm{~m}$ above bed affected by the strong wind on August 10 to 12, 2009. It shows that the maximum SSC at stations of $\mathrm{S} 1(-3 \mathrm{~m})$, $\mathrm{S} 2(-5.5 \mathrm{~m})$ and $\mathrm{S} 3(-8 \mathrm{~m})$ were respectively $1.532 \mathrm{~kg} / \mathrm{m}^{3}$, $0.837 \mathrm{~kg} / \mathrm{m}^{3}$, and $0.411 \mathrm{~kg} / \mathrm{m}^{3}$ during the whole process of strong wind, and all the maximum appeared almost at the same. Obviously, the distribution of SSC presents a decreasing trend with the increase of the water depth. And the SSC at the depth of $8 \mathrm{~m}$ under the theoretical lowest level is very low even during the action of strong wind wave.

In addition, the position of surf zone was calculated by wave data, bathymetric data and wave breaking index[7]. Results show that the surf zone is generally limited on shallow shoals with depth smaller than $3 \mathrm{~m}$ under the theoretical level, and only larger waves, for example once in 10 years with wave height of about $4.0 \mathrm{~m}$, break on the shoals with water depth smaller than $5.3 \mathrm{~m}$ under the theoretical lowest level.

In order to reduce the amount of sediment entering the port from the entrance of breakwater, breakwater gap should be in area outside of the surf zone, with low SSC even in time of with larger wind wave. Therefore, the position of breakwater head should be on the shoals with depth of $5 \mathrm{~m}$ to $8 \mathrm{~m}$ under the theoretical lowest level.

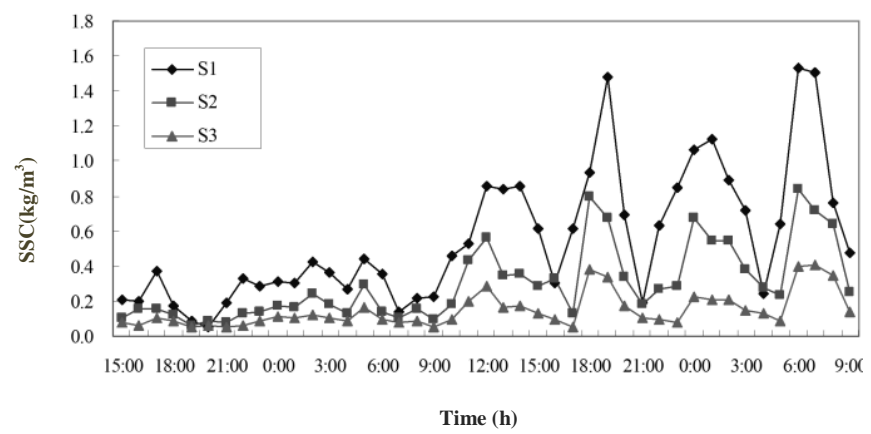

Fig. 4. Time variation of suspend sediment concentration (SSC) at the height of $0.5 \mathrm{~m}$ above bed under the action of strong wind on August 10 to 12, 2009.

\section{3) Layout of breakwater}

After the determination of overall layout of the breakwater, schemes with different breakwater lengths, and directions of some breakwater segments were studied and optimized through the numerical model and physical model. Finally, the optimal layout was determined as shown in Fig.5. In addition, considering the actual situation of the port development, the construction of breakwater is divided into two stages, namely Starting projects and Planning projects.

Only one breakwater will be built in the Starting projects, named Northern breakwater or A as shown in Fig. 5. The direction of Northern breakwater is 160 to 340 degrees, and breakwater lengths are about $6.3 \mathrm{~km}$, and the breakwater head locates on the depth of $6.7 \mathrm{~m}$. Meantime, four berths with levels of 50000 tons are designed on the south side of the breakwater, which bottom elevations are $-11.5 \mathrm{~m}$.

The breakwater entrance of the Planning projects locates on the depth of $7.0 \mathrm{~m}$, and two other breakwaters will be constructed with the name B and C as shown in Fig. 5.

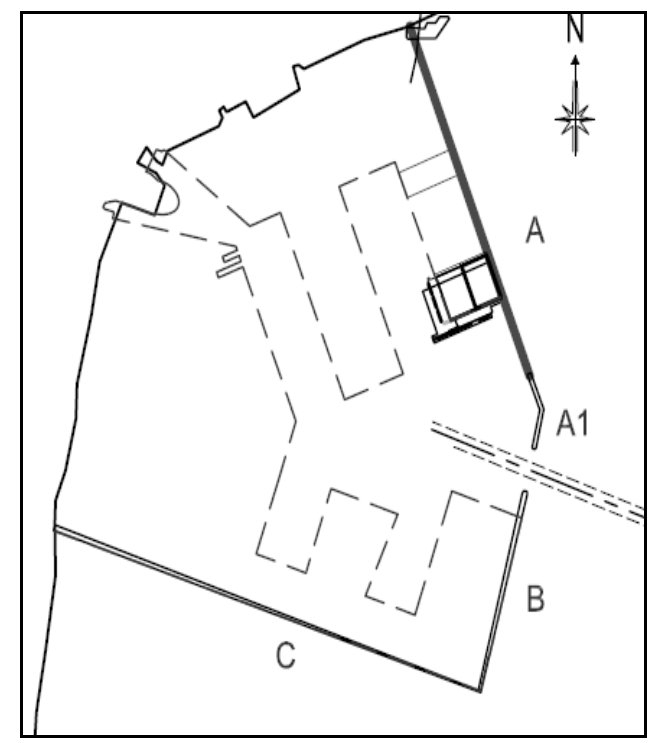

Fig. 5. Schematic diagram of breakwater layout.

B. Changes of Hydrodynamic Conditions and Sediment Caused by Construction of Breakwater

1) Construction of the starting projects 


\section{a) Variation of Wave height}

Fig.6 (Top) is the variation of annual average wave height under the average tidal level before and after the Northern breakwater, which shows that the area south to the breakwater is sheltered significantly from $\mathrm{N}$ to $\mathrm{E}$ waves, and the ranges of sheltering effect are about $12 \mathrm{~km}$.

\section{b) Variation of tidal current}

The effect of breakwater on the flow is significant. In the period of flooding tide, the maximum current velocity near the breakwater head reaches $1.2 \mathrm{~m} / \mathrm{s}$ due to the deflection, and a clockwise backflow formed in the south side of breakwater. The variation of mean velocity of the spring tide before and after the project is shown in Fig. 6 (Bottom), which indicates that the effect of the breakwater, wharf and channel on the flow is limited to the area near the engineering.

c) Variation of the surrounding topography

Since the tidal current velocity and wave height on the south side of the breakwater will attenuate largely after the Northern breakwater building, it will be conducive to the settle of suspend sediment, resulting in elevation of terrain, which will be further feedback to the wave propagation to decrease the wave height.

The excavation of harbor basin and channel destroys the original balance system of water and sediment, resulting of sediment deposition. It is predicted that the annual average deposition intensity of the harbor basin as well as the berth might be about $0.69 \mathrm{~m}$, and the one of channel might be 0.32 m.
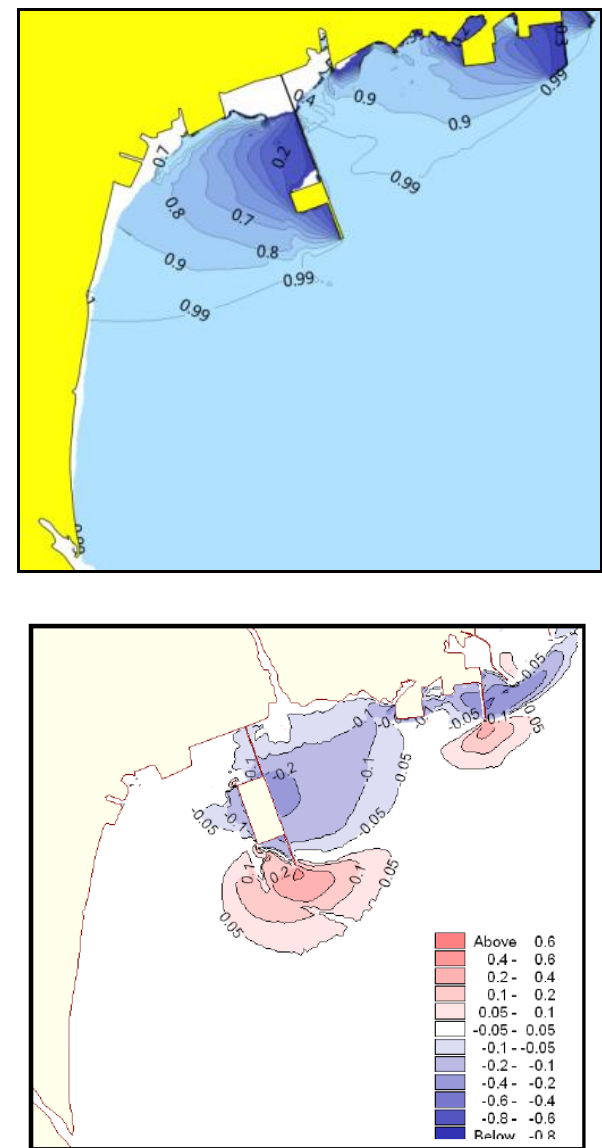

Fig. 6. (Top) the annual average wave height attenuation rate before and after the Starting projects under the average level; (Bottom) variation of mean velocity of the spring tide before and after the Starting projects, and breakwater of Lanshan port north to Ganyu Port Area as well.

\section{2) Construction of the planning projects \\ d) Variation of wave height}

Fig.7 (Top) is the annual average wave height attenuation rate before and after the Planning projects construction under the average level, showing that waves reduce greatly in harbor basin. Therefore, the purpose of breakwater can be achieved. Nevertheless, the wave heights in the area south to the breakwater $\mathrm{C}$ also decrease a little, which might affect the beach.
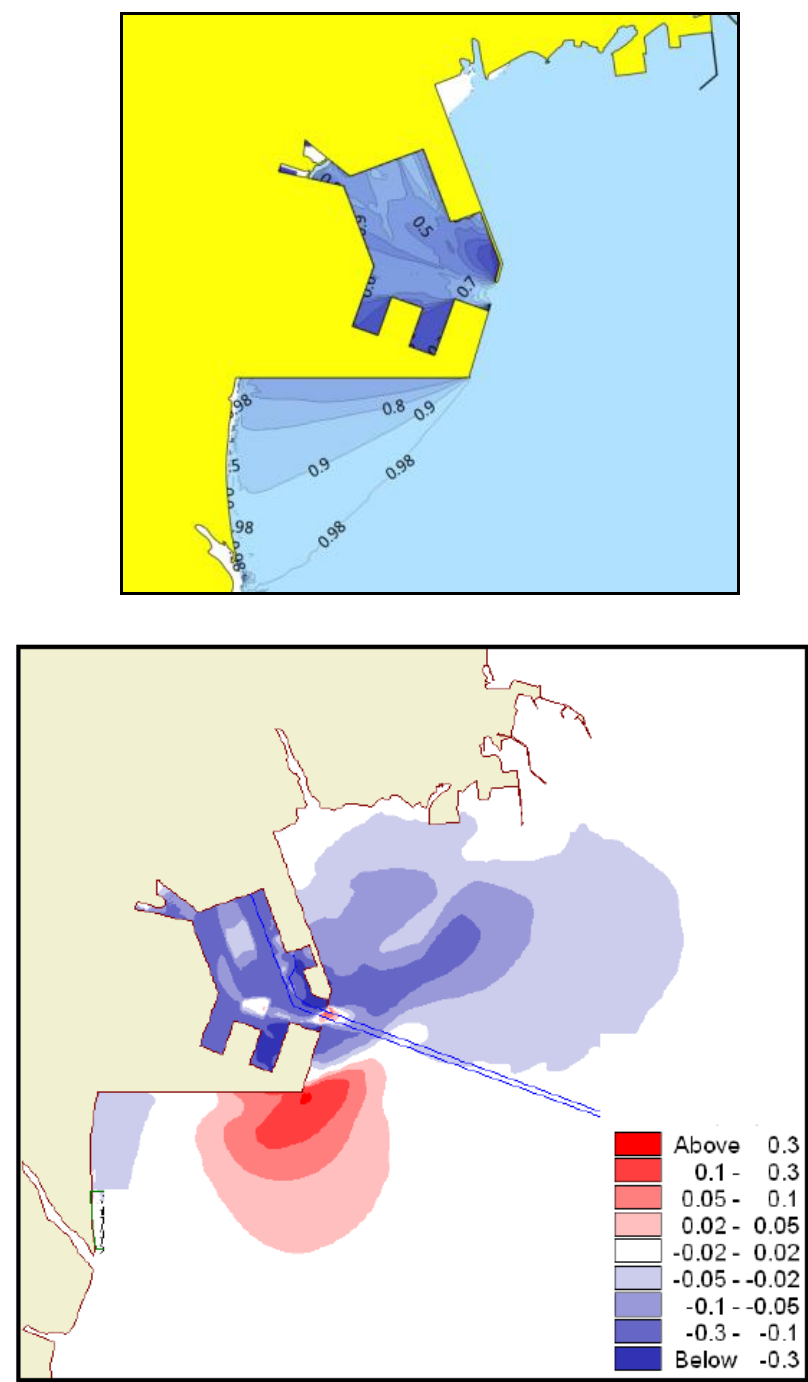

Fig. 7. (Top) the annual average wave height attenuation rate before and after the Planning projects under the average level; (Bottom) variation of mean velocity of the spring tide before and after the planning projects.

\section{2) Variation of flow}

The average flow velocity at the entrance of Planning projects is about $0.65 \mathrm{~m} / \mathrm{s}$, and the maximum is $1.09 \mathrm{~m} / \mathrm{s}$. Fig. 7 (Bottom) is the flow velocity difference before and after the planning project, showing that the velocity of flow increases greatly nearby the breakwater entrance, as well as the area near the corner of breakwater B and C. While the velocity of flow in the harbor basin, and the area north of the breakwater A. The maximum impact ranges are approximately $20 \mathrm{~km}$ $* 16.5 \mathrm{~km}$.

\section{3) Sediment}

In harbor basin, the largest sediment deposition appears in the region close to the entrance. The annual siltation of harbor basin is $0.15 \sim 0.23 \mathrm{~m} / \mathrm{a}$. In outer channel, the largest 
siltation lies on the $1 \mathrm{~km} \sim 3 \mathrm{~km}$ outside of the entrance, and the annual average siltation is about $0.30 \mathrm{~m} / \mathrm{a}$.

\section{VERIFIED BY THE ACTUAL VARIATION OF TERRAIN}

The Starting projects have been completed in December 2012, and the actual variation of topography can be used to analyze the rationality of the breakwater layout.

According to the satellite remote sensing image and the field investigation, the shoals on the south side especially near the breakwater end have rose significantly, and have been covered with spartina, showing a clear trend of deposition [9]. Hence, the hydrodynamic conditions are very weak in these areas, suggesting that the shelter efficiency of the Northern breakwater is great.

The annual average siltation calculated with water depth of harbor basin and berth surveyed at different time is about $0.40 \mathrm{~m} \sim 0.60 \mathrm{~m}[9]$, which is close to the predicted value of $0.69 \mathrm{~m}$, illustrating that the predicted results are basically credible. Meantime, the smaller siltation intensity indicates that the layout of Northern breakwater and harbor berth of the Starting projects is reasonable.

\section{CONCLUSION}

Sediment siltation is a common problem of harbors in the open muddy coast. Hence, many harbors have built two long dikes to reduce the siltation, for example, Main Port Area of Lianyungang Harbor, and Tianjin Harbor etc.[10]. of course, breakwater also needs to meet the requirements of wave prevention. For a new harbor, or an old harbor which need to be rebuilt or expanded, the layout of breakwater is an important question. This paper concludes the methods to determine the layout of Ganyu Port Area of Lianyungang Harbor, including the determination of key parameters such as breakwater direction, and position of breakwater head etc. and optimization of scheme, and verification by the investigation after the construction of engineering. These methods might be as reference for the design of breakwater in other muddy coast, especially the determination of breakwater head position. Similarly, the methods still need to be verified and improved continually by more other engineering.

\section{ACKNOWLEDGMENT}

Author thanks N. Zhang, H.M. Zhao, C. Cui, et al who take part in the numerical model and physical model tests of scheme optimization.

\section{REFERENCE}

[1] I. Irie, R. Hidayat, K. Morimoto, and N Ono, "Study of Siltation Protection in Asian Ports," in Proc. the Twelfth International Offshore and Polar Engineering Conference, pp. 539-544, Japan, 2002

[2] Q. X. Pang, R. B. Zhang, and H. Yang, "Flume experimental study on the heights of submerged dike to diminish siltation," The Ocean Engineering, vol. 30, no. 2, pp. 66-71, 2012

[3] Y. F. Jiang, "Design of the breakwater," Port and Waterway Engineering, vol. 9, no. 4, pp. 26-32, 1980.

[4] M. B. Abbott, H. M. Petersen, and O. Skovgaard, "On the numerical modelling of short waves in shallow water," Journal of Hydraulic Research, vol. 16, no. 3, pp. 173-204, 2010

[5] P. A. Madsen, R. Murray, and O. R. Sørensen, "A new form of the boussinesq equations with improved linear dispersion characteristics," Coastal Engineering, vol. 15, no. 4, pp. 371-388, 1991.

[6] N. Zhang, S. H. Zuo, Q. X. Pang, and H. Yang, " Research on sediment problems in initial project in Ganyu port area of lianyungang port," China Harbour Engineering, vol. 15, no. 2, pp. 15-21, 2012.

[7] Q. X. Pang, S. H. Zuo, and N. Zhang, "Report of engineering sediment problems in starting project in Ganyu port area of lianyungang harbor,' Tianjin Research Institute of Water Transport Engineering, Tianjin, China, 2009.

[8] Q. X. Pang and H. X. Xin, "Study on the factors affecting suspend sediment concentration during large wind wave in the muddy coast," Journal of Hydro-dynamics, vol. Ser. A, 26, no. 4, pp. 413-421, 2011.

[9] H. M. Zhao and G. T. Liu, "Report of effect of Ganyu port area of lianyungang harbor on the surrounding hydrodynamic and sediment conditions and sea beach," Tianjin Research Institute of Water Transport Engineering, Tianjin, China, 2014.

[10] J. Y. Jiang, Q. X. Pang, and N. Zhang, "Research process of sediment engineering of Tianjin Harbor, " Beijing, China Communications Press, 2016.

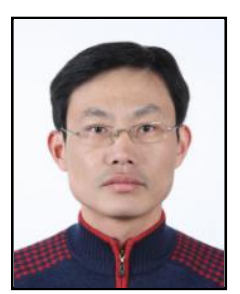

Qixiu Pang was born in Weifang, Shandong Province, China on August 29, 1977. He received his Ph.D. in harbor, coastal and offshore engineering from Tianjin University, Tianjin, China, in 2012. He received his Master in harbor, coastal and offshore engineering from Hohai University of, Nanjing, China, 2005.

$\mathrm{He}$ is a associate researcher of Tianjin Research Institute of Water Transport Engineering at No. 2618, Xingang erhao road, Binhai new Area, Tianjin, China. His books include: Q. X. Pang, "Formation and motion characteristics of fluid mud and counter measurements," Beijing, China Communications Press, 2013. J. Y. Jiang, Q. X. Pang, and N. Zhang, "Research process of sediment engineering of Tianjin Harbor," Beijing, China Communications Press, 2016. His current research interests are mainly the cohesive sediment in Engineering.

Dr. Pang has been awarded the First Prize "Science and technology prize of the China water transportation construction association, 2015", and the Second Prize of "Science and technology award of China Institute of Navigation, 2015". 